\title{
Indications and practical application of strategies in the endovascular management of intracranial aneurysms
}

\author{
Marco Antonio Zenteno ${ }^{1}$, Jorge Arturo Santos-Franco ${ }^{2}$, Ángel Lee ${ }^{3}$, \\ Fernando Vinuela ${ }^{4}$, Jose-Maria Modenesi Freitas ${ }^{5}$, Luis Rafael Moscote- \\ Salazar ${ }^{6}$ \\ ${ }^{1}$ Chairman of the Department of Neurological Endovascular Therapy of the Instituto Nacional \\ de Neurología y Neurocirugía "Manuel Velasco Suárez". Profesor of Neurological Endovascular \\ Therapy at the Universidad Nacional Autónoma de México. Comprehensive Stroke Unit, \\ Hospital Ángeles del Pedregal. \\ Address: Insurgentes Sur 3877, Colonia La Fama, México DF, CP: 14269. Phone: 5606. 9755, \\ Fax: 5135. 5144, e-mail: mazente@yahoo.com.mx,dr_angel_lee@yahoo.de; \\ ${ }^{2}$ Department of Neurosurgery at the Centro Médico Nacional "La Raza”, Assistant Professor in \\ Neurosurgery at the Universidad Nacional Autónoma de México; \\ ${ }^{3}$ Comprehensive Stroke Unit, Hospital Ángeles del Pedregal; Department of Neurosurgery, \\ Instituto Nacional de Ciencias Médicas y Nutrición, Salvador Zubirán, Mexico City, 14000, \\ Mexico; \\ ${ }^{4} \mathrm{MD}$, Director Interventional Neuroradiology, Ronald Reagan UCLA Medical Center; \\ Professor of Radiology at the University of California Los Angeles, USA; \\ ${ }^{5} \mathrm{MD}$, Departments of Neuroradiology and Neurological Endovascular Therapy, Brazil; \\ ${ }^{6} \mathrm{MD}$, Universidad de Cartagena, Cartagena de Indias, Colombia.
}

\begin{abstract}
The occlusion of intracranial aneurysms is more successful and stable by properly planning the approach and application of endovascular techniques. The next step is a relentless analysis of the different indications of endovascular treatment, tailoring a strategy suitable for the specific case, and making more rational choices for
\end{abstract}

the management of aneurysms. Indications and strategies according to the analysis of the aneurysmal complex are given, as well as pros and cons of the endovascular technique according to different anatomical locations.

Key words: Aneurysms, subarachnoid hemorrhage, embolization, endovascular management, aneurysmal complex

Current perspectives in the endovascular management of intracranial aneurysms. Indications and practical application of strategies

\section{Introduction}

The endovascular treatment of intracranial aneurysms (AIs) has proven to be safe and effective (1-4) and can therefore be chosen as a first option in many cases.
Nevertheless, the features of some aneurysms turn the interventional option more risky and/or less effective than surgical management. A deep knowledge of the aneurysmal complex (5) and the 
availability of new endovascular devices allows us to devise new strategies and pose less arbitrary indications for the endovascular management of IA. The "aneurysmal complex" is a novel concept and embraces three elements never considered as a whole before: 1) the aneurysm, 2) the parent vessel, 3) the morphological, geometric and hemodynamic relationship of both.

The endovascular perspective must focus on the aneurysmal complex, (5) formed by the sac, the parent vessel and the neck of the aneurysm. It has been suggested that clinical surveys should report not only the shape of the aneurysm, but also that of the parent artery and the configuration in detail. (6)

Endovascular treatment should focus on modifying the structure of the vessel, (i. e. the reconstruction of the parent vessel through the modification of the anatomy or vascular architecture) and hemodynamic factors. The new endovascular approach must target the relationship between of the aneurysm to the parent vessel.

\section{Endovascular techniques}

In the first part of this series, we already have explained the morphological and hemodynamic mechanisms underlying the development of IA. We also reviewed some of the available tools for the management of this serious disorder. From that analysis, we can mention that the current endovascular approach includes three different perspectives: intra-aneurysmal, vascular reconstruction or combined.
1. Intra-aneurysmal management: The goal is the mere exclusion of the aneurismal sac, without modifying the hemodynamic or the anatomic features of the parent vessel. To achieve this procedure, two different techniques have been described: the simple coiling (Figure 1 ) and the balloon-assisted (Figure 2, panels A-D) or balloon-remodelling technique (5, 7). Both techniques will no induce permanent modification of the geometry/anatomy or laminar flow. The simple coiling is suitable in aneurysms with small necks able to hold the mesh of coils, while balloon-assisted technique is indicated in wide-neck aneurysms, with the only purpose of preventing the coils of migrating to the parent vessel lumen. An additional remark is that in many cases of wide-neck aneurysms the embolization with 3-D, complex and $360^{\circ}$ coils may prove useful and successful, without further assistance of additional devices. (Figure 1, panels G-I)

\section{Vascular reconstruction}

This is a procedure intentionally modifying the flow pattern from the parent vessel (hemodynamic factor) to induce the thrombosis in the aneurysm. In some other cases, an intentional modification of the anatomical and hemodynamic pattern is needed. In both situations, the indicated approach is the sole stenting technique, or other flow diversion techniques (Figure 4) (8-14). 

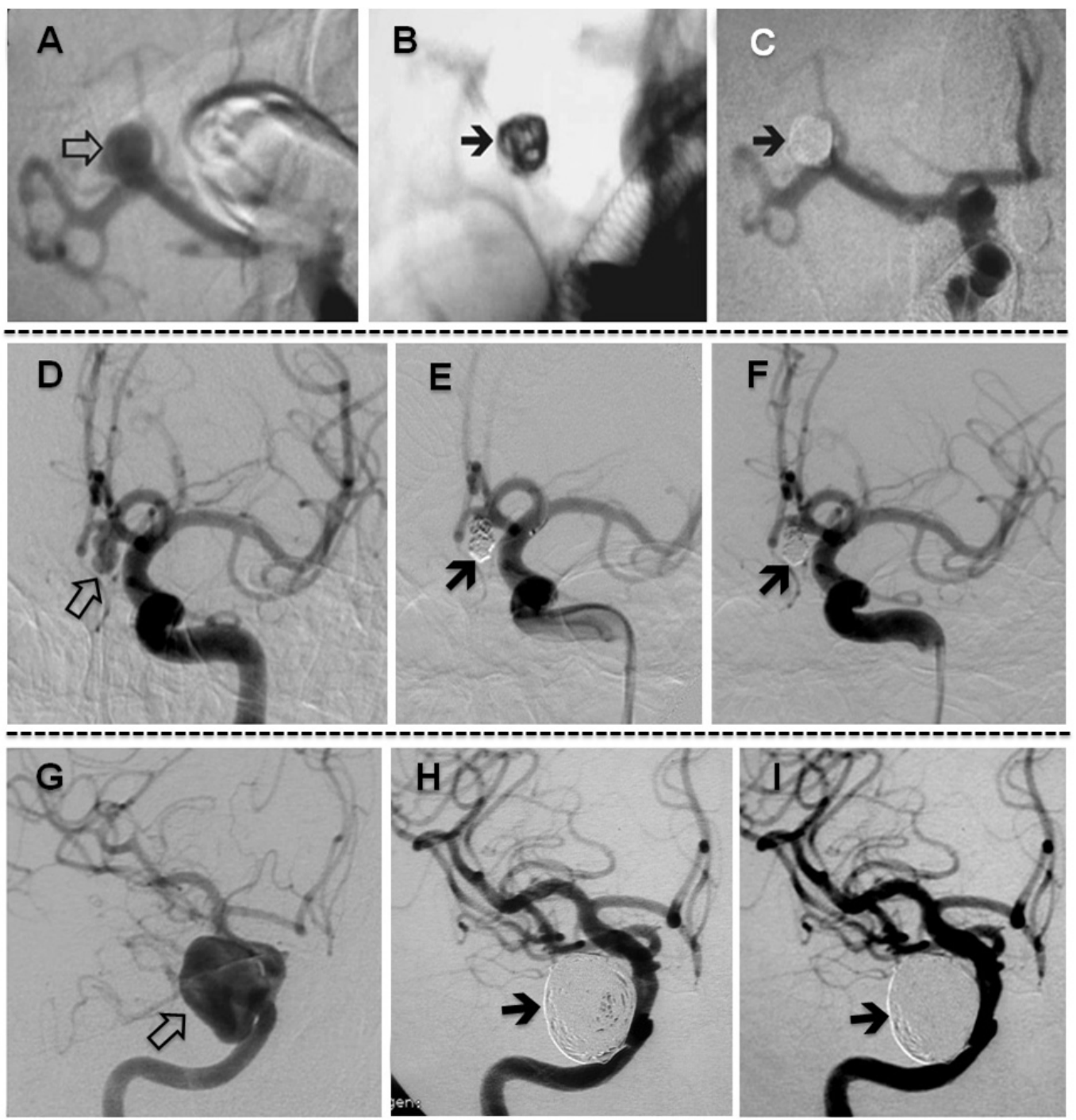

\section{Figure 1}

Simple coiling

A-C: Right middle cerebral artery (MCA) bifurcation. A: Preoperative angiogram of a wide-neck ruptured aneurysm (hollow arrow). B: 3-D coils frame a basket to be filled with helical coils (thick arrow). C: Complete exclusion of the aneurysm.

D-F: Ruptured aneurysm of the anterior communicating artery D: A wide-neck aneurysm is shown (hollow arrow). E: Again, 3-D complex coils (thick arrow) allow an uneventful procedure. F: One year follow-up control angiogram shows no recanalization (thick arrow).

G-I: Giant aneurysm of the cavernous segment of right ICA. G: The dimensions of the lesion (hollow arrow) allow the placement of coils within the sac. H: Subtotal occlusion (thick arrow) is obtained with GDC $360^{\circ}$ coils. I: One year follow-up confirms the stability of embolization (thick arrow). 

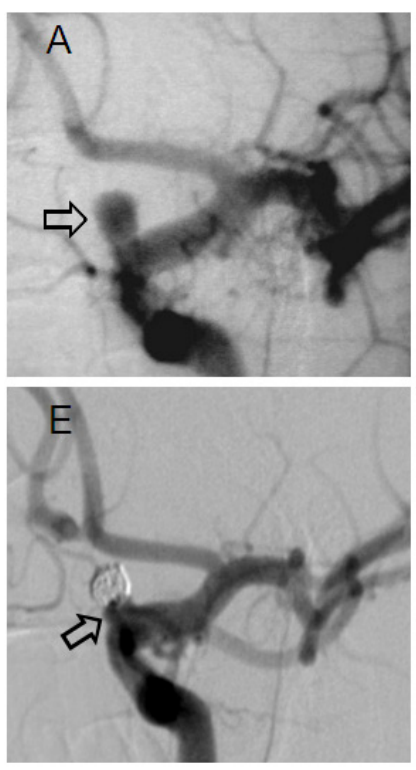

Left ophthalmic ruptured aneurysm. The patient was going to be operated (hydrocephalus) and therefore stenting was not feasible (antiplatelet drugs needed).

A-D: Balloon-remodelling.

A: Wide-neck lesion (hollow arrow) not suitable for simple coiling. B: A Hyperform balloon (Micro

Therapeutics, Inc.,Irvine, CA) is placed at the neck (thin arrow) and a microcatheter is placed into the sac (dotted arrow). C: The inflated balloon (thin arrow) prevents herniation of coils (dotted arrow) into the parent vessel lumen. D: The final run shows a small residual neck.

E-H: Self-expandable stent placement

E: At 6 months follow-up, recanalization (hollow arrow) is observed from coil compactation. F: The selfexpandable stent (thick arrow) Leo plus (Balt Extrusion, Montmorency, France) is placed across the neck. G:

Final run shows no immediate changes in residual neck (hollow arrow). H: At another 6 months, however, complete occlusion is observed.

3. Combined approach: stent-assisted coiling combines the advantages of the abovementioned techniques: a previously coiled aneurysm which is stented or viceversa. (Figure 3). This technique has been in use for more than a decade (15) and is constantly improving: when the sole stenting technique did not occlude the aneurysm and it must be coiled in a second step $(7,10,8,11)$ in those cases, an insufficient correction of the geometric/hemodynamic relationships of the aneurysmal complex may be the cause of such failures. When both techniques are combined, the thrombosis of the aneurysm is favored by coiling and the stability is maintained by stenting, trying thus to avoid a later recanalization. (Figure 5)

\section{Indications and strategies according to the analysis of the aneurysmal complex}

The aneurysmal complex as previously defined is the target of the endovascular strategy and must be treated according to a careful analysis of its different components: aneurysmal sac, parent vessel, neck of the aneurysm. Their respective relationships and the angles of the aneurysm with respect to the parent vessel are key factors. 

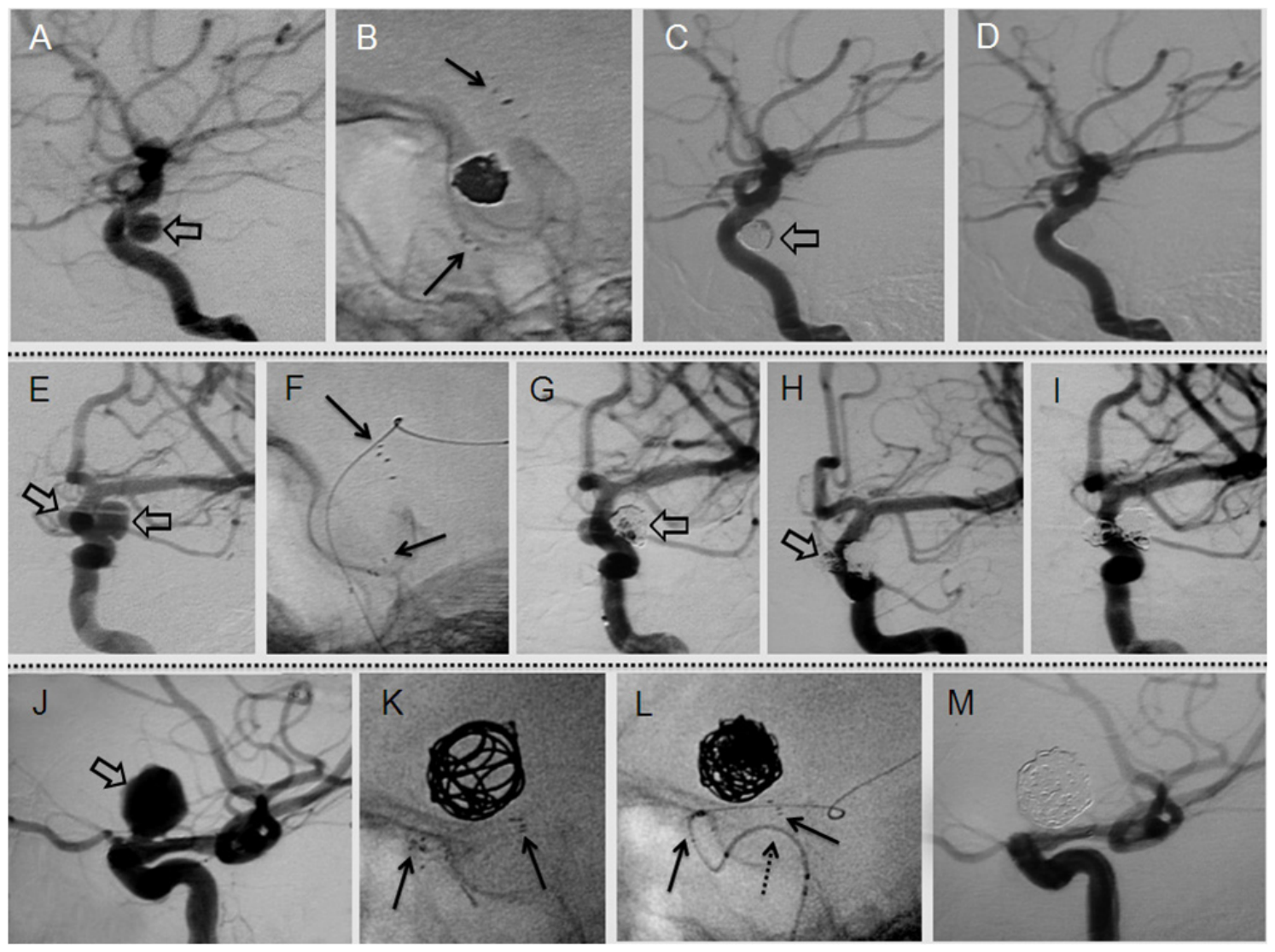

Figure 3

Stent-assisted embolization

A-D: Incidental left carotid cave aneurysm.

A: Apparently small neck lesion (hollow arrow). B: During their placement, the coils tended to protrude and therefore a self-expandable Neuroform3 stent (black arrows) was needed (Boston Scientific, Natick, MA). C: Final run shows 95\% embolization (hollow arrow), while, D: One year follow-up confirms definitive occlusion.

The stent acts as a scaffold. E-I: Incidental left ophthalmic segment multiple aneurysms

E: Their wide-necks (hollow arrows) suggest a large vessel wall defect. F: A self-expandable Neuroform3 (Boston Scientific, Natick, MA) stent (arrows) is deployed. G: One aneurysm (hollow arrow) then another is coiled. H: Final run shows $90 \%$ occlusion (hollow arrow) of both lesions. I: One year control shows total and stable occlusion. The stent allows parent vessel reconstruction. J-M: Giant aneurysm of left ophthalmic segment

(dorsal carotid) J: The lesion is partially thrombosed (hollow arrow) and recanalization is frequent in this location, and therefore, simple coiling was not option. K: A self-expandable Neuroform3 (Boston Scientific, Natick, MA) stent (black arrows) was placed at the neck and the lesion embolized with coils. L: Immediate post-operative control showed patency of the aneurysm and a second Neuroform3 stent (dotted arrow) was then navigated, overlapping the first stent (black arrows), M: Six months follow-up angiogram shows permanent occlusion of the aneurysm. 

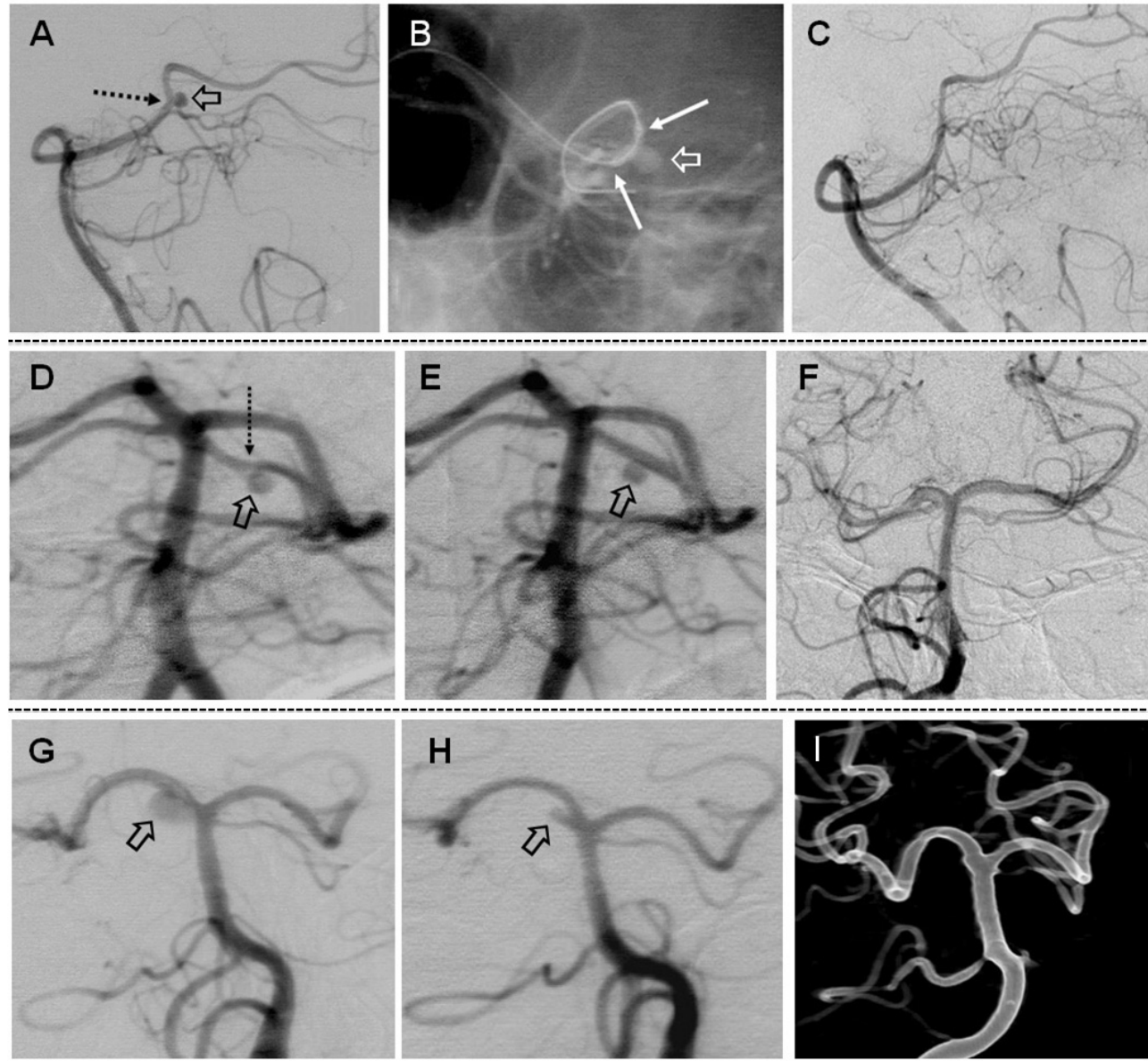

Figure 4

Sole stenting: These figures were already published in the quoted references.

A-C: P2-P3 segment of the left posterior cerebral artery (PCA)

A: This distal lesion (hollow arrow) arises at an angle (dotted arrow) of the PCA. B: Contrast stasis within the aneurysm (hollow arrow) can be seen after the placement of a balloon-expandable Pharos stent (Micrus Corp., Sunnyvale, CA) at the neck of the lesion. C: Six-month control angiogram shows permanent occlusion of the aneurysm and a change in the geometric shape of the parent vessel is clearly seen.

Zenteno M, Modenesi Freitas JM et al. Balloon-expandable stenting with and without coiling for wide-neck and complex aneurysms. Surg Neurol. 2006 Dec;66(6):603-10; discussion 610.

D-F: Lesion of the two first segments of the left superior cerebellar artery (SCA).

D: A ruptured aneurysm (hollow arrow) arises at an angled portion (dotted arrow) of the parent vessel. E: After the placement of a stent, contrast stasis (hollow arrow) is appreciated within the aneurysm and the segment is straightened. F: One year follow-up shows complete thrombosis of the aneurysm.

Zenteno M, Santos-Franco J et al. Superior cerebellar artery aneurysms treated using the sole stenting approach. Technical note. J Neurosurg. 2007 Oct;107(4):860-4

G-H: Lesion at the angle of the PCA and SCA.

G: Partially thrombosed aneurysm (hollow arrow). H: The deployement of a self-expandable Neuroform3 stent (Boston Scientific, Natick, MA) leads to progressive thrombosis at 3 months (hollow arrow). I: One year control angiogram demonstrates complete occlusion. SES do not modify geometry, but hemodynamic factors like wall shear stress, inflow and outflow.

Zenteno MA, Santos-Franco JA et al. Use of the sole stenting technique for the management of aneurysms in the posterior circulation in a prospective series of 20 patients. J Neurosurg. 2008 Jun;108(6):1104-18. 

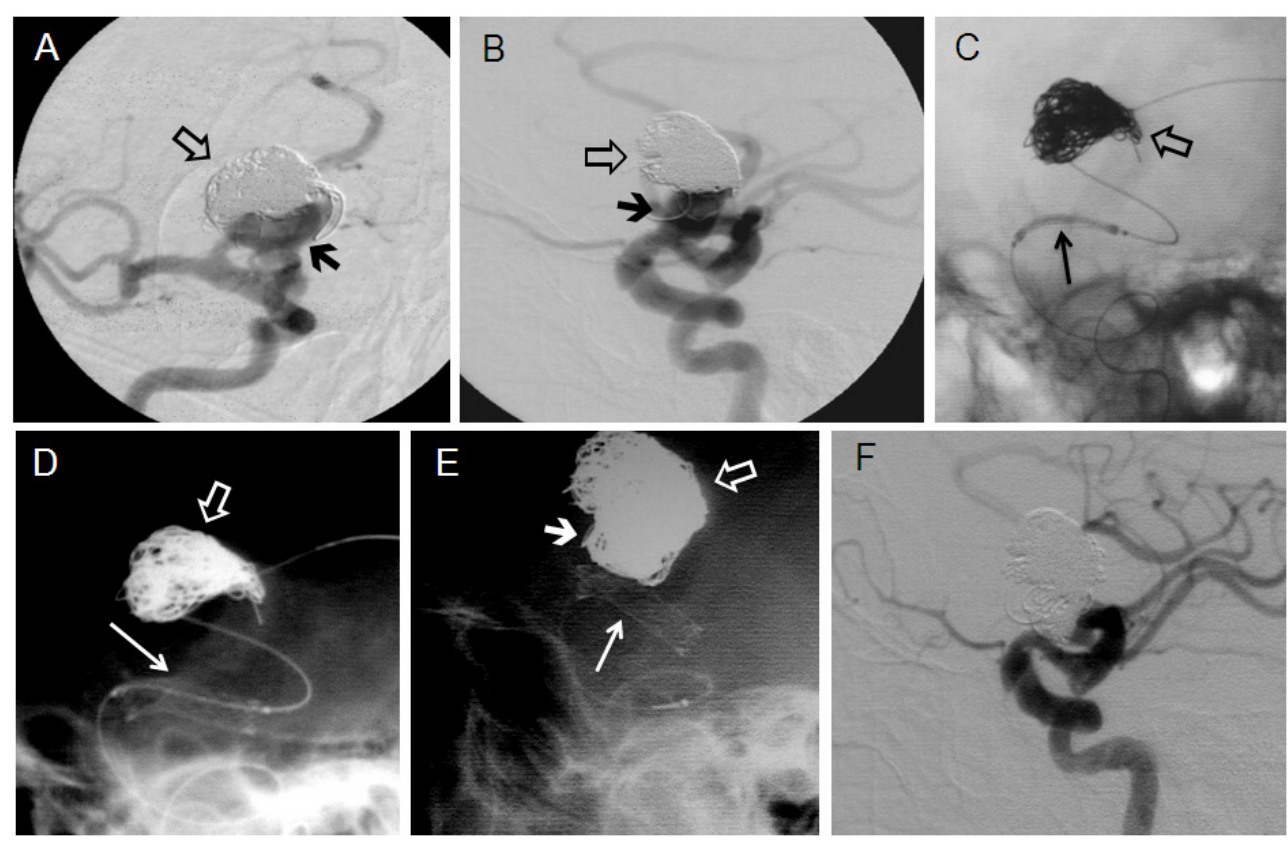

Figure 5

Recanalization and retreatement of a right ophthalmic segment large aneurysm (Figures already published) A (oblique) \& B (lateral): Angiography of recanalization showing the compaction of coils (hollow arrows) and large residual neck (thick arrows). C: Lateral view during the navigation of a balloon-expandable Pharos (Micrus Corp., Sunnyvale, CA) stent (thin arrow) and compacted coils (hollow arrows). D \& E: Deployed stent (thin arrow), further coiling (thick arrow) and previous (hollow arrows). F: Six-month control shows stable occlusion.

Zenteno M, Modenesi Freitas JM et al. Balloon-expandable stenting with and without coiling for wide-neck and complex aneurysms. Surg Neurol. 2006 Dec;66(6):603-10; discussion 610.

\section{A) Aneurysmal sac:}

\section{Status of the aneurysmal sac}

Unruptured lesions. In this case, a more liberal approach is possible concerning the use of stents, as antiplatelet drugs may be used under less constraints. Moreover, the absence of vasospasm allows a better analysis of the morphology of the aneurysmal complex.

Ruptured lesions. In these cases, the clinical status of the patients and other factors related to the rupture must be carefully evaluated, especially with a rigorous pre-treatment imaging work-up. These factors are subarachnoid hemorrhage (SAH), intracranial hematomas (intraparenchymal, subdural, epidural), intraventricular bleeding, hydrocephalus, cerebral edema, and the severity of vasospasm, with its ischemic consequences. (Figure 6) Patients who present a spaceoccupying lesion with mass effect should be operated for evacuation of the hematoma and, whenever possible, to secure the aneurysm. We should be especially cautious in selecting the candidates for the placement of a stent either for sole stenting or for stent-assisted coiling, because antiplatelet drugs are mandatory in those cases, preventing these patients from being operated without the risk of bleeding complications (cf. intra-stent thrombosis and antiplaltelet drugs, in the first part of this series). In such cases, balloon remodeling may be an interesting option.

The clinical condition of the patient should be carefully assessed. (16) 

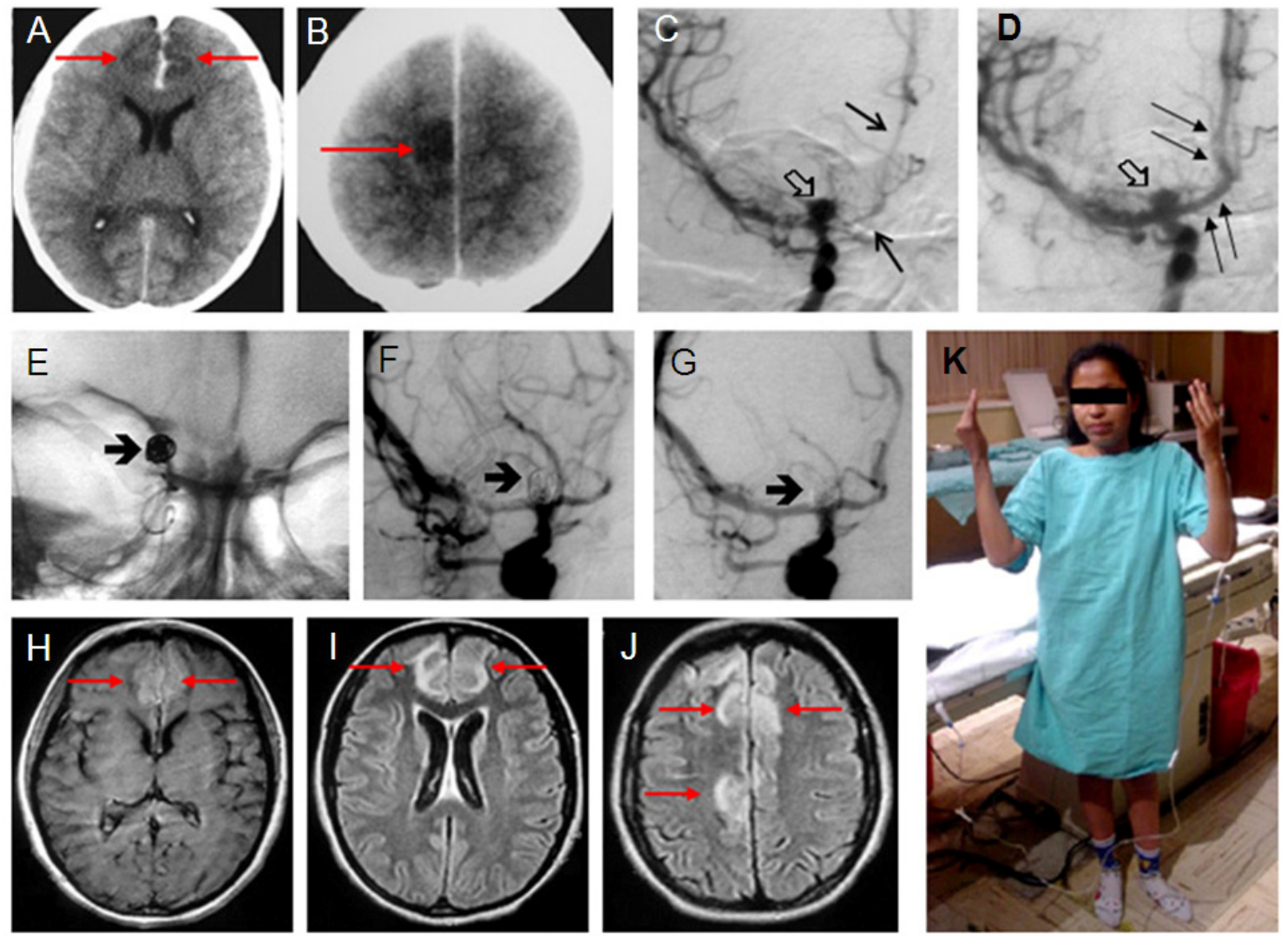

Figure 6

Endovascular management of severe vasospasm due to a ruptured aneurysm.

A \& B: Hypodense areas in the territory of both anterior cerebral arteries (ACAs). C \& D: Ruptured aneurysm (hollow arrow) of the carotid bifurcation. Severe vasospasm (black arrows) of both ACAs, with recovery of normal vessel diameter (paired thin arrows) after intra-arterial infusion of nimodipine. E-G: The aneurysm (thick arrow) was embolized. H-J: MRI confirmed hypoperfusion of pericallosal arteries territory (red arrows).

K: The patient fully recovered, in spite of preoperative paraparesia.

TABLE 1

Suitability of interventional management according to the size of aneurysmal sac and neck

\begin{tabular}{|c|c|c|c|}
\hline Size of the sac & Appropriateness & Size of the ostium & Appropriateness \\
\hline$<2 \mathrm{~mm}$ & + & Small & +++++ \\
\hline Small & +++++ & Large & +++++ \\
\hline Large & ++++ & L & \\
\hline Giant & +++ & L
\end{tabular}

Patients with grade I and II in the Hunt and Kosnik scale use to be good candidates for interventional management, while in grade $\mathrm{V}$ patients, any kind of definitive management is an ethical issue. Grade III/IV patients are potential candidates. In these cases, we should precisely inquire about the events which are involved in the 
impairment of clinical conditions; for instance, vasospasm can frequently be held responsible for this impairment and pharmacological (17) or mechanical angioplasty may be a resource to be used for the rescue of the patient. (Figure 6) Patients with mass effect due to a hematoma and/or clinically unstable hydrocephalus are poor candidates to interventional management; however, small hematomas which do not produce mass effect or intracranial hypertension $(\mathrm{ICH})$ or hydrocephalus not causing $\mathrm{ICH}$ can be good candidates to embolization. The technique to be used must be tailored to the specific features of the aneurysm: size, (table 1) neck width, (table 2) configuration of the parent vessel, and so on. Concerning this particular point, we can mention that intentionally partial embolization with coils may provide a transient protection of the sac against further rupture, to prevent rebleeding in patients who cannot undergo a normal vessel reconstruction because of their clinical status or when surgery is not an option (poor clinical status, vasospasm, severe comorbidities). In such patients, the aneurysm can be secondarily secured later using either approach. Patients with a previous bleeding (Hunt and Kosnik grade 1A) whose aneurysm has not been secured can be considered from that point of view as non ruptured aneurysms.

\section{Size}

Aneurysms have traditionally categorized according to size: $(18,19)$ for grading aneurysmal size, we use the recently published standard of the AHA(4) (small aneurysms $(<5 \mathrm{~mm})$ medium aneurysms $(5>\mathrm{X}<15 \mathrm{~mm})$, large aneurysms $(15>\mathrm{X}$ $<25 \mathrm{~mm}$ ) and giant aneurysms $(\mathrm{X}>25$ $\mathrm{mm})$.

Smaller than $2 \mathrm{~mm}$ : These lesions are poor candidates to coil embolization, as coils below this diameter are not available, and periprocedural risk of rupture is high. Another option may be surgical wrapping, but this surgical technique has not shown enough evidence in the prevention of rebleeding.

\section{TABLE 2}

Suitability of interventional management depending on location in anterior/posterior circulation

\begin{tabular}{|c|c|}
\hline \multicolumn{2}{|c|}{ Anterior circulation } \\
\hline Location & Appropriateness \\
\hline Cavernous & +++++ \\
\hline Paraclinoid & ++++ \\
\hline PCom & +++++ \\
\hline ICA Bifurcation & ++++ \\
\hline proximal MCA & ++++ \\
\hline MCA bifurcation & ++ \\
\hline distal MCA & ++++ \\
\hline ACom & ++++ \\
\hline ACA bifurcation & ++++ \\
\hline distal ACA & ++++ \\
\hline
\end{tabular}

\begin{tabular}{|c|c|}
\hline \multicolumn{2}{|c|}{ Posterior circulation } \\
\hline Location & Appropriateness \\
\hline Vertebral & +++++ \\
\hline VB junction & +++++ \\
\hline proximal basilar & +++++ \\
\hline distal basilar & +++++ \\
\hline$\star$ PICA & +++ \\
\hline$\star$ AICA & +++ \\
\hline$\star$ SCA & +++ \\
\hline basilar bifurcation & +++++ \\
\hline
\end{tabular}




\begin{abstract}
PCom: posterior communicating segment, ICA: internal carotid artery, MCA: middle cerebral artery, Acom: anterior communicating artery, ACA: anterior cerebral artery; VB: vertebrobasilar, PICA: posteroinferior cerebellar artery, AICA: anteroinferior cerebellar artery, SCA: superior cerebellar artery.

$\star$ : proximal segments of these arteries are highly accessible to interventional management

Table legends: + : poor, ++ : low,++ : indicated with reserve, ++++ : good indication, +++++ : excellent indication
\end{abstract}

In such cases, surgical wrapping has not shown enough evidence to prevent rebleeding. (4) On the endovascular side, the redirection of flow seems the best option, and the sole stenting technique allows to treat both the diseased parent vessel and induce the thrombosis of the aneurysm. Zenteno et al report a risk of $5 \%$ for rebleeding after sole stenting in posterior circulation aneurysms. (8)

If the aneurysmal SAH is associated to a complication requiring a surgical management, the sole stenting technique is relatively contraindicated. (cf. integrity of the aneurysmal sac).

Small aneurysms: there are good candidates for embolization. Simple coiling is a viable option, because they usually harbor a small neck; other factors have must play a role, like vectors, flow direction, aspect and status of the parent vessel, to avoid recanalization. Aneurysms at some particular locations are a good example to illustrate our hypothesis: 1) aneurysms of the ophthalmic segment of the internal carotid artery (ICA), located at the dorsal wall of the supraclinoid ICA, 2) basilar tip, 3) ICA bifurcation. They behave as terminal lesions, and even small aneurysms with a small neck do recanalize in spite of an initial good coiling, because hemodynamic and morphologic/geometric factors were not considered. (Figures $2 \& 5$ )

The use of stents as ancillary tools in those cases may prove useful and prove stable and lasting results. (Figure 3, panels $\mathrm{J}-\mathrm{M})(11,20)$.
The following factors are additional elements which may suggest a beneficial effect of a vascular reconstruction with a stent or another flow diverter: wide-neck, unfavorable geometry, or a diseased parent vessel.

Large and giant aneurysms: Their natural history is marked by high rates of morbidity and mortality, and must be secured in spite of procedure related risks. (21) Giant aneurysms are a challenge to endovascular management: (19) 1) they require the use of multiple devices, increasing risks and costs; 2) mass effect after embolization may improve in most cases, but some exceptions have been reported. (22) The coiling of such lesions may worsen cranial nerve compression, while as in other cases symptoms improve; no clear factors explaining this ambiguity had been elucidated till recently, (22) 3) in some cases the neck is large, involves an important part of the parent vessel circumference and will therefore include rami which might be occluded when treated. $(19,23)$ The majority of complications and treatment failures occur in this kind of aneurysms, even if surgical rates of morbidity and mortality are not really lower. (19) In the pretherapeutic workup of giant aneurysms, balloon occlusion tests are fundamental in the assessment of collateral circulation. (24)

Collateral circulation is inadequate when the angiographic delay between the venous drainage of the injected and the occluded hemisphere was not $>2$ seconds or when 
clinical manifestations of hypoxia are present. (25) The occlusion of the parent vessel is sometimes the definitive treatment, (26-35) The current development of endovascular techniques and devices allows to avoid parent vessel sacrifice and is the last resource which should be applied only when other strategies have failed. The endovascular approach can range from simple coiling (Figure 1, panels G-I), stentassisted embolization (Figure 3, panels J$\mathrm{M})$, vascular reconstruction or a combined approach. (Figure 5)

Parent vessel occlusion (PVO) must be the last resource. Long-term effects of PVO have not been evaluated, and may be less indicated in younger patients or in the elderly: the development of de novo aneurysms in such patients has recently been described. (36)

There are some cases where a vascular reconstruction is the most suitable solution: 1) very large neck (cf. ostium), 2) lesions arising at a dysplasic segment of the vessel, or with adverse geometry/hemodynamics. By acting so, the likelihood of coil compaction and recanalization of the lesion may be decreased. Another good option to prevent compaction and recanalization may be the use of the HydroCoil (37) embolization system. (Figure 5) In some cases of wide-neck aneurysms, there is no need to modify the anatomic/hemodynamic features of the lesion and a plain coiling with $3-\mathrm{D}$, complex or $360^{\circ}$ coils may prove sufficient. (Figure 1, panels G-I) Giant aneurysms often harbor intrasaccular thrombi, (38) and therefore a distal migration of emboli is possible during embolization procedures. $(39,40)$ for the preoperative imaging workup of such aneurysms, magnetic resonance imaging (MR) and computed tomography angiography (CTA) are a useful tool for the assessment of these aneurysms, and the stent can act as a barrier to prevent the migration of thrombi. Several cases of giant aneurysms successfully managed with sole stenting technique or other flow diverters have been reported. $(12,14)$ New devices like the X-calibur Aneurysm Occlusion Device (Merlin MD, Ltd, Singapore) have been developed and clinical trials in humans have started. (Zenteno, unpublished data)

\section{B) Ostium:}

The ostium or neck is the area where blood enters into (inflow) and comes out from (out-flow) the aneurysm. This is the precise location where muscular fibers and internal elastic lamina are weakened and progressively disappear into the sac. A large neck has been defined when it is above 4 $\mathrm{mm}$ or dome/neck ratio is below 1. 5. (41)

1. Small ostium: they are suitable for simple coiling without the need of any additional device.

When the lesion is located in a curved segment or in a dysplasic segment of the vessel, the placement of the stent may help in modifying the geometry or treating the diseased vessel (v. g. in some aneurysms of the ophthalmic segment of the ICA or at the basilar tip). In posterior circulation aneurysms with a small neck, the SS technique has shown to be an effective technique. $(8,11)$

2. Large ostium: a large neck is responsible for the exaggerated growth of the aneurysm, as it allows recirculation of blood, resulting in the fatigue of the wall of the sac; it is therefore not a coincidence if large or giant aneurysms usually have large necks. On the other side, the forces generated by blood flow are higher at the distal portion of the neck, favoring the 
rupture of the aneurysm. (42) Compactation and recanalization are both favored by the dynamic force on already embolized aneurysms. For these reasons, we relieve that the stent is mandatory in presence of such necks. Additionally, when the geometry is unfavorable, we recommend the use of a balloon expandible stent (BES). (Figure 4) (8-11) In cases of acute $\mathrm{SAH}$ with a contraindication for the placement of a stent, the simple coiling can be initially performed to protect the sac with different techniques, either balloon remodelling (Figure 2) or with 3-D, complex or $360^{\circ}$ coils. The placement of a stent can be done later in a second procedure, once the complications of the acute stage have passed an a safe stenting is possible (cf. integrity of the sac).

\section{C) Parent Vessel:}

We are sure that once the parent vessel has been modified with any vascular reconstruction technique, the embolization of IA will be a definitive and successful management of these lesions. We are aware of the controversy behind these concepts.

1. Anatomic and geometric aspects: La reconstruction with a stent is highly recommended and is sometimes required in cases where the vessel has an irregular shape or seems truly dysplasic. When the lesion arises at the top of an angle or at the convexity of a curved segment of the parent vessel, the straightening of that segment is recommended to shift the flow away from the diseased wall and decrease the inflow into the aneurysm; (Figures $3 \& 4$ ) a BES is efficient in the supraclinoid ICA, while the SES has shown the ability to correct the geometry of vessels distal to the circle of Willis. (8-11) Beyond their role of an ancillary tool in stent-assisted coil embolization, stents can decrease the rates of recanalization due to the modification of geometric and hemodynamic aspects. In these situations, the SS technique can also be used, especially in incidental aneurysms. The role of the SS technique in giant aneurysms has to be defined in larger series; our group has a unique example of total occlusion with a 10 years angiographic and clinical follow-up. (14)

2. Hemodynamic aspect. The hemodynamic phenomena are responsible for the birth and development of aneurysms. As soon as the vascular geometry is changed by the stent, the force vectors of dynamic and static pressures on the vascular wall are also modified. (8-11, 43-50) Additionally, the stents modify the laminar flow and decrease the WSS, therefore slow and even prevent the growth of the aneurysm.

This phenomenon is better visualized in sidewall aneurysms or in lesions which do not receive a direct effect of flow impact. As far as we have observed, the low radial force of SES leads to an imperfect wall apposition, leading to a definitive change of the WSS. The modification of the hemodynamic pattern leads to an intraaneurysmal stasis, thrombosis and occlusion of the aneurysm, as we have shown several times in previous publications. $(8-11,14)$

In cases with previous coiling, the stent decreases the impact of the dynamic forces of blood flow against the coils' mesh, thus decreasing the likelihood of recanalization. $(11,19,20)$

\section{D) Location of the aneurysmal complex}

1. Anterior circulation: Most of them are accessible to embolization. (table 3 ) The two locations which have traditionally represented a challenge to interventional management are anterior communicating 
artery and middle cerebral artery bifurcation aneurysms. Their neck is often large and their anatomy is is a little bit more complex to allow an uneventful deployment of a stent.

Anterior comunicating artery complex harbors hypothalamic and chiasmatic tiny vessels, which represent a technical challenge to both techniques. Their occlusion leads to complex clinical situations like the hypothalamic syndrome or a massive motor deficit, as during the occlusion of the recurrent artery of Heubner. The technical development of complex and $360^{\circ}$ coils, (Figure 1, panels D-F) the balloon remodeling with compliant devices and SES have largely improved the performance of interventional management of aneurysms at this location.

In the MCA bifurcation, surgery has classically yielded better results; the use of remodeling provides promising results in selected cases. (unpublished data, Dr. Freitas).

2. Posterior circulation: (table 4) In several comparative analyses, the endovascular technique offers better anatomical results, with a more favorable clinical evolution and shorter hospital stays, compared to the open surgical approach. (1, 2, 51-53) more than half of lesions originate at the basilar tip or at the junction of the vertebral artery (VA) and the posteroinferior cerebellar artery (PICA). $(18,54)$

Vertebral and posteroinferior cerebellar artery (PICA):

The vertebral aneurysms are of a relatively simple access to interventional management, and assisted - or simple coiling may be both applied, vascular reconstruction. The aneurysms of the posterior communicating artery itself are rare, but many of them can have large dimensions even if the parent vessel has a small diameter.

The interventional management of PICA aneurysms is feasible in the two first segments, where simple coiling or stentassisted coiling are readily available. Endovascular therapy cannot easily reach the distal segments, unlike surgery with suboccipital, retrosigmoid and far lateral approaches. (55) in these aneurysms, interventional neuroradiology offers an alternative for the parent vessel occlusion (PVO) when surgery is not indicated.

Anteroinferior cerebellar artery (AICA): They represent less than $1 \%$ of all IA. (56)

Thanks to the development of microguidewires and microcatheters, the aneurysms of the premeatal segment (57) are more accessible and may be embolized with coils. Their management remains a challenge in case of large necks: stentassisted coil embolization is tough because the parent vessel is the tortuous and its diameter is small, making of PVO a possible solution. The meatal and postmeatal segment (57) are less accessible to interventional radiology: the occlusion of the two first segments of the AICA can lead to stroke of the lateral aspect of the brainstem, the middle cerebellar peduncle, the cerebellar hemisphere and cranial nerves VII/VIII complex. The occlusion of the post-meatal portion is more benign because of more profuse collateral anastomoses of AICA with PICA branches. No specific pattern predictive of good collaterality exists, but a dominant PICA may be a clue. (55)

Superior cerebellar artery (SCA): they barely account for about $0.2 \%$ of all IAs. (Figure 4) $(18,57,58)$ Most of them are 
saccular, even if fusiform and dissecting lesions are also encountered. (59-63)

The endovascular approach is less timeconsuming and the access to the first two segments (anterior pontine and ambiens) of the ACS is without technical difficulties, even if more distal segments are harder to catheterize. (10) The reports of ACS aneurysms treated by embolization are scarce, $(10,64,65)$ and in some of them PVO has been the only solution.

This parent vessel sacrifice must be performed in case the aneurysms originated at the distal segments (quadrigeminal and cortical), because the occlusion of proximal segments may involve not just the cerebellar hemisphere, but the tegmentum of the pons, the superior cerebellar peduncles and the dentate nucleus. $(55,66)$

Our group has reported the successful management of aneurysms of the first segment of the ACS with the SS technique, and those are the only reported cases in the world literature. (10)

Basilar trunk (BT): Aneurysms of the BT located at the origin of the SCA or the AICA, are often mistaken as being properly aneurysms of those arteries and are very accessible to embolization procedures. Simple coiling may be the suitable solution, but as large necks are common, the placement of a stent is often recommended. The use of the SS technique has shown effective results in well selected cases, (8, 14) even if more experience of the operator is needed. (Figure 4, panels G-I) In spite of the advancements of the technique and the endovascular devices, sometimes the only solution is PVO to promote the thrombosis of the aneurysm. For this kind of maneuver, balloon test occlusion is mandatory for an adequate assessment of the collateral supply.
Basilar apex: Roughly 19\% of the cases use to be giant lesions generally with a large neck, $(67,68)$ thereby with poor coil retention. Their morphology is less spherical and more irregular, while their "T-shaped" configuration favors the hemodynamic factors tending to promote recanalization. Several technical attempts have been devised to overcome these obstacles, and the most efficient is the placement of a single stent or of more devices in "Y"-configuration stenting technique for adequate coil support (69) and deviation of hemodynamic forces. (70) Short term results are promising, but a longer follow-up is mandatory, to define the recanalization rate. (68)

Dissecting aneurysms of the vertebrobasilar system:

Two different kinds of approaches can be performed: deconstructive and reconstructive procedures. (71-75) the first type requires PVO with coils and/or detachable balloons. (34, 76-89) To perform such procedures, a BTO is required. When the aneurysm is located at the level of the origin of PICA or of the anterior spinal artery, or when collateral circulation is insufficient, the PVO can be contraindicated. When collateral circulation is poor, a surgical by-pass can be an additional tool. $(77,82,83,88,89)$ Even if such procedures are an efficient technique with good long term results, late severe complications like ischemic lesions of the brainstem or retrograde recanalization have been described. (34, 73, 77, 81-83, 89-94)

Reconstructive procedures try to occlude the aneurysm while keeping patent the flow in the parent vessel. (72, 75, 95) Stentassisted embolization appears feasible and suitable. $(15,50,96,97)$ The SS technique has already been reported for a successful 
management of dissecting aneurysms. (71) Zenteno et al prospectively treated 11 such patients, with curative resultats in $90.9 \%$ of the cases, with a one year follow-up. (8) Ahn et al describe their experience of 9 years with 13 cases of dissecting aneurysms of the vertebral artery. (75) In 9 cases, dissections were exclusively managed with a stent, and the other 4 with a double stent. In angiographic follow-up of 6 and 12 months they showed a complete occlusion in one half of the cases, and the other half remained stable in spite of an incomplete occlusion. These authors underline the fact that the cases with angiographic cure are those with a double stent. Other authors also suggest a double stenting/overlapping stents as a way to increase the likelihood of occlusion. (98) The sole stenting technique not only preserves the flow of vessels arising from the stented segment, buy also occasionally allows to visualize vessels which were previously not seen befote the placement of the stent. $(8,10)$

\section{Conclusions}

The available devices and better understanding of the diseases have progressively transformed most of the IA amenable to an endovascular management under acceptable conditions of morbidity and mortality and with immediate anatomic results which range from fair to excellent. The new deal for the interventionalist must be targeted at finding strategies which will decrease the rates of recanalization. The techniques of vascular remodelling and the use of devices which modify the hemodynamic and morphologic features (stents, flow diverters, flow modifiers) have shown results which are promising, safe, effective and durable beyond the one year follow-up period. Longer and more rigorous follow-up is needed to determine the precise rates of recanalization and rebleeding in these new directions of management.

\section{References}

1. Molyneux AJ, Kerr RS, Birks J, et al. Risk of recurrent subarachnoid haemorrhage, death, or dependence and standardised mortality ratios after clipping or coiling of an intracranial aneurysm in the International Subarachnoid Aneurysm Trial (ISAT): long-term follow-up. Lancet Neurol 2009;8:427-433.

2. Molyneux A, Kerr R, Stratton I, et al. International Subarachnoid Aneurysm Trial (ISAT) of neurosurgical clipping versus endovascular coiling in 2143 patients with ruptured intracranial aneurysms: a randomised trial. Lancet 2002;360:1267-1274.

3. Meyers PM, Schumacher HC, Higashida RT, et al. Indications for the Performance of Intracranial Endovascular Neurointerventional Procedures: A Scientific Statement From the American Heart Association Council on Cardiovascular Radiology and Intervention, Stroke Council, Council on Cardiovascular Surgery and Anesthesia, Interdisciplinary Council on Peripheral Vascular Disease, and Interdisciplinary Council on Quality of Care and Outcomes Research. Circulation 2009;119:2235-2249.

4. Bederson JB, Connolly ES, Jr. , Batjer HH, et al. Guidelines for the Management of Aneurysmal Subarachnoid Hemorrhage: A Statement for Healthcare Professionals From a Special Writing Group of the Stroke Council, American Heart Association. Stroke 2009;40:994-1025.

5. Santos-Franco JA ZM, Lee A, Viñuela F, Modenesi Freitas JM. Current approaches in the endovascular management of intracranial aneurysms. Part I: Basic concepts. Rev Invest Clin 2011;63:in press.

6. Sato K IY, Ishikawa T, Matsuki N, Yamaguchi T. The importance of parent artery geometry in intraaneurysmal hemodynamics. Med Eng Phys 2008 Jul;30:774-782.

7. Moret J, Cognard C, Weill A, Castaings L, Rey A. [Reconstruction technic in the treatment of wide-neck intracranial aneurysms. Long-term angiographic and clinical results. Apropos of 56 cases]. J Neuroradiol 1997;24:30-44.

8. Zenteno MA, Santos-Franco JA, Freitas-Modenesi $\mathrm{JM}$, et al. Use of the sole stenting technique for the management of aneurysms in the posterior circulation in a prospective series of 20 patients. J Neurosurg 2008;108:1104-1118.

9. Zenteno MA, Murillo-Bonilla LM, Guinto G, et al. 
Sole stenting bypass for the treatment of vertebral artery aneurysms: technical case report. Neurosurgery 2005;57:E208; discussion E208.

10. Zenteno M, Santos-Franco J, Aburto-Murrieta Y, et al. Superior cerebellar artery aneurysms treated using the sole stenting approach. Technical note. J Neurosurg 2007;107:860-864.

11. Zenteno M, Modenesi Freitas JM, Aburto-Murrieta Y, Koppe G, Machado E, Lee A. Balloon-expandable stenting with and without coiling for wide-neck and complex aneurysms. Surg Neurol 2006;66:603-610; discussion 610.

12. Lylyk P, Miranda C, Ceratto R, et al. Curative Endovascular Reconstruction of Cerebral Aneurysms With the Pipeline Embolization Device: the Buenos Aires Experience. Neurosurgery 2009;64:632-643 610. 1227/1201. NEU. 0000339109. 0000398070. 0000339165.

13. Fiorella D, Lylyk P, Szikora I, et al. Curative cerebrovascular reconstruction with the Pipeline embolization device: the emergence of definitive endovascular therapy for intracranial aneurysms. J NeuroInterv Surg 2009;1:56-65.

14. Zenteno M, Gomez CR, Santos-Franco J, Vinuela F, Aburto-Murrieta Y, Lee A. Ten-year follow-up of giant basilar aneurysm treated by sole stenting technique: a case report. J Med Case Reports 2010;4:64. 15. Higashida RT, Smith W, Gress D, et al. Intravascular stent and endovascular coil placement for a ruptured fusiform aneurysm of the basilar artery. J Neurosurg 1997;87:944-949.

16. Hunt WE, Kosnik EJ. Timing and perioperative care in intracranial aneurysm surgery. Clin Neurosurg 1974;21:79-89.

17. Biondi A, Ricciardi GK, Puybasset L, et al. IntraArterial Nimodipine for the Treatment of Symptomatic Cerebral Vasospasm after Aneurysmal Subarachnoid Hemorrhage: Preliminary Results. AJNR Am J Neuroradiol 2004;25:1067-1076.

18. Locksley HB. Natural History of Subarachnoid Hemorrhage, Intracranial Aneurysms and Arteriovenous Malformations. J Neurosurg 1966;25:321-324.

19. Gonzalez NR, Duckwiler G, Jahan R, Murayama Y, Vinuela F. Challenges in the Endovascular Treatment of Giant Intracranial Aneurysms. Neurosurgery 2006;59:S3-113-S113-124.

20. Lubicz B, Bandeira A, Bruneau M, Dewindt A, Baleriaux D, De Witte O. Stenting is improving and stabilizing anatomical results of coiled intracranial aneurysms. Neuroradiology 2009;51:419-425.

21. Drake CG, Peerless SJ, Ferguson GG. Hunterian proximal arterial occlusion for giant aneurysms of the carotid circulation. J Neurosurg 1994;81:656-665.

22. Panagiotopoulos V, Ladd SC, Gizewski E, et al.
Recovery of Ophthalmoplegia after Endovascular Treatment of Intracranial Aneurysms. AJNR Am J Neuroradiol 2010:ajnr. A2281.

23. Guglielmi G, ViÃ \pm uela F, Duckwiler G, et al. Endovascular treatment of posterior circulation aneurysms by electrothrombosis using electrically detachable coils. J Neurosurg 1992;77:515-524.

24. van Rooij WJ, Sluzewski M, Slob MJ, Rinkel GJ. Predictive Value of Angiographic Testing for Tolerance to Therapeutic Occlusion of the Carotid Artery. AJNR Am J Neuroradiol 2005;26:175-178.

25. Abud DG, Spelle L, Piotin M, Mounayer C, Vanzin JR, Moret J. Venous Phase Timing during Balloon Test Occlusion as a Criterion for Permanent Internal Carotid Artery Sacrifice. AJNR Am J Neuroradiol 2005;26:2602-2609.

26. Fox AJ, ViÃ \pm uela F, Pelz DM, et al. Use of detachable balloons for proximal artery occlusion in the treatment of unclippable cerebral aneurysms. J Neurosurg 1987;66:40-46.

27. Debrun G, Fox A, Drake C, Peerless S, Girvin J, Ferguson G. Giant unclippable aneurysms: treatment with detachable balloons. AJNR Am J Neuroradiol 1981;2:167-173.

28. Aymard A, Gobin YP, Hodes JE, et al. Endovascular occlusion of vertebral arteries in the treatment of unclippable vertebrobasilar aneurysms. J Neurosurg 1991;74:393-398.

29. Higashida RT, Halbach VV, Dowd CF, Barnwell SL, Hieshima GB. Intracranial aneurysms: interventional neurovascular treatment with detachable balloons--results in 215 cases. Radiology 1991;178:663670 .

30. Gobin YP, Viñuela F, Gurian JH, et al. Treatment of large and giant fusiform intracranial aneurysms with Guglielmi detachable coils. J Neurosurg 1996;84:55-62. 31. Kuether TA, Nesbit GM, Barnwell SL. Clinical and angiographic outcomes, with treatment data, for patients with cerebral aneurysms treated with Guglielmi detachable coils: a single-center experience. Neurosurgery 1998;43:1016-1025.

32. Sluzewski M, Brilstra EH, van Rooij WJ, Wijnalda D, Tulleken CA, Rinkel GJ. Bilateral vertebral artery balloon occlusion for giant vertebrobasilar aneurysms. Neuroradiology 2001;43:336-341.

33. Lubicz B, Leclerc X, Levivier M, et al. Retractable Self-expandable Stent for Endovascular Treatment of Wide-necked Intracranial Aneurysms: Preliminary Experience. Neurosurgery 2006;58:451-457.

34. Leibowitz R, Do HM, Marcellus ML, Chang SD, Steinberg GK, Marks MP. Parent Vessel Occlusion for Vertebrobasilar Fusiform and Dissecting Aneurysms. AJNR Am J Neuroradiol 2003;24:902-907.

35. Steinberg GK, Drake CG, Peerless SJ. Deliberate basilar or vertebral artery occlusion in the treatment of 
intracranial aneurysms. J Neurosurg 1993;79:161-173. 36. Jin SC, Choi CG, Kwon DH. Development of 'De novo' Aneurysm after Therapeutic Carotid Occlusion. J Korean Neurosurg Soc 2009;45:236-239.

37. Deshaies EM, Adamo MA, Boulos AS. A prospective single-center analysis of the safety and efficacy of the HydroCoil embolization system for the treatment of intracranial aneurysms. J Neurosurg 2007; 106:226-233.

38. Cohen JE, Rajz G, Umansky F, Spektor S Thrombosis and recanalization of symptomatic nongiant saccular aneurysm. Neurol Res 2003;25:857859.

39. Lubicz B, Leclerc X, Gauvrit J-Y, Lejeune J-P, Pruvo J-P. Giant Vertebrobasilar Aneurysms: Endovascular Treatment and Long-term Follow-up. Neurosurgery 2004;55:316-326.

40. Knuckey NW, Haas R, Jenkins R, Epstein MH. Thrombosis of difficult intracranial aneurysms by the endovascular placement of platinum-Dacron microcoils. J Neurosurg 1992;77:43-50.

41. Horowitz MB LE, Kassam A, Purdy PD. Endovascular Therapy for Intracranial Aneurysms: A Historical and Present Perspective. In: Horowitz MB LEe, ed. Neuroendovascular Surgery. Basel: Karger, 2005: 101-121.

42. Burleson AC, Turitto VT. Identification of quantifiable hemodynamic factors in the assessment of cerebral aneurysm behavior. On behalf of the Subcommittee on Biorheology of the Scientific and Standardization Committee of the ISTH. Thromb Haemost 1996;76:118-123.

43. Doerfler A, Wanke I, Egelhof T, Stolke D, Forsting M. Double-stent method: therapeutic alternative for small wide-necked aneurysms. J Neurosurg 2004;100:150-154.

44. Houssay BA. Circulación arterial. In: Fisiología Humana, 7th ed. Buenos Aires: El Ateneo, 2000: 220241.

45. Geremia G, Haklin M, Brennecke L. Embolization of experimentally created aneurysms with intravascular stent devices. AJNR Am J Neuroradiol 1994;15:12231231.

46. Sadasivan C, Lieber BB, Gounis MJ, Lopes DK, Hopkins LN. Angiographic Quantification of Contrast Medium Washout from Cerebral Aneurysms after Stent Placement. AJNR Am J Neuroradiol 2002;23:12141221.

47. Wakhloo AK LB, Stancampiano AP, Hopkins LN. Effect of intravascular stents on flow characteristics in an aneurysm model. Circulation 1996;94:59.

48. Wakhloo AK, Tio FO, Lieber BB, Schellhammer F, Graf M, Hopkins LN. Self-expanding nitinol stents in canine vertebral arteries: hemodynamics and tissue response. AJNR Am J Neuroradiol 1995;16:1043-1051.
49. Wakhloo AK, Schellhammer F, de Vries J, Haberstroh J, Schumacher M. Self-expanding and balloon-expandable stents in the treatment of carotid aneurysms: an experimental study in a canine model. AJNR Am J Neuroradiol 1994;15:493-502.

50. Wakhloo AK, Lanzino G, Lieber BB, Hopkins LN. Stents for Intracranial Aneurysms: The Beginning of a New Endovascular Era? Neurosurgery 1998;43:377379.

51. Lanzino G, Fraser K, Kanaan Y, Wagenbach A. Treatment of ruptured intracranial aneurysms since the International Subarachnoid Aneurysm Trial: practice utilizing clip ligation and coil embolization as individual or complementary therapies. J Neurosurg 2006;104:344-349.

52. Heros RC. Clip ligation or coil occlusion? J Neurosurg 2006;104:341-343.

53. Johnston SC, Wilson CB, Halbach VV, et al. Endovascular and surgical treatment of unruptured cerebral aneurysms: comparison of risks. Ann Neurol 2000;48:11-19.

54. McCormick WF, Nofzinger JD. Saccular Intracranial Aneurysms. J Neurosurg 1965;22:155-159. 55. Rhoton AL, Jr. The Cerebellar Arteries. Neurosurgery 2000;47:S29-S68.

56. Gonzalez LF, Alexander MJ, McDougall CG, Spetzler RF. Anteroinferior Cerebellar Artery Aneurysms: Surgical Approaches and Outcomes-A Review of 34 Cases. Neurosurgery 2004;55:1025-1035.

57. Pritz MB. Aneurysms of the anterior inferior cerebellar artery. Acta Neurochirurgica (Wien) 1993;120:12-19.

58. Allcock. Aneurysms. In: Newton TH PDe, ed. Radiology of the skull and the brain. St. Louis: Mosby, 1974: 2449-2489.

59. Duncan IC. Clinically occult chronic dissecting aneurysm of the superior cerebellar artery in a child. Pediatr Radiol 2005;35:1118-1120.

60. Danet M, Raymond J, Roy D. Distal Superior Cerebellar Artery Aneurysm Presenting with Cerebellar Infarction: Report of Two Cases. AJNR Am J Neuroradiol 2001;22:717-720.

61. Ikeda K, Shoin K, Taguchi H, Yamano J, Kawahara R. Postpartum dissecting aneurysm of the superior cerebellar artery--case report. Neurol Med Chir (Tokyo) 1999;39:852-857.

62. Hirose Y, Nakamura T, Takamiya Y, Kinoshita N, Hirai H. Fusiform superior cerebellar artery aneurysm presenting with contralateral abducens nerve paresis-case report. Neurol Med Chir (Tokyo) 1990;30:119122.

63. Kalyan-Raman UP, Kowalski RV, Lee RH, Fierer JA. Dissecting Aneurysm of Superior Cerebellar Artery: Its Association With Fibromuscular Dysplasia. Arch Neurol 1983;40:120-122. 
64. Ishikawa E, Yanaka K, Meguro K, et al. [Treatment of peripheral aneurysms of the posterior circulation]. No Shinkei Geka 2000;28:337-343.

65. Chaloupka JC, Putman CM, Awad IA. Endovascular therapeutic approach to peripheral aneurysms of the superior cerebellar artery. AJNR Am J Neuroradiol 1996;17:1338-1342.

66. Luhan JA, Pollack SL. Occlusion of the Superior Cerebellar Artery. Neurology 1953;3:77-.

67. Ogasawara K, Kubo Y, Tomitsuka N, et al. Treatment of vertebral artery aneurysms with transposition of the posterior inferior cerebellar artery to the vertebral artery combined with parent artery occlusion. J Neurosurg 2006;105:781-784.

68. Lozier AP, Connolly ES, Jr. , Lavine SD, Solomon RA. Guglielmi Detachable Coil Embolization of Posterior Circulation Aneurysms: A Systematic Review of the Literature. Stroke 2002;33:2509-2518.

69. Rohde S, Bendszus M, Hartmann M, Hahnel S. Treatment of a wide-necked aneurysm of the anterior cerebral artery using two Enterprise stents in " $\mathrm{Y}$ "configuration stenting technique and coil embolization: a technical note. Neuroradiology 2010;52:231-235.

70. Perez-Arjona E, Fessler RD. Basilar artery to bilateral posterior cerebral artery 'Y stenting' for endovascular reconstruction of wide-necked basilar apex aneurysms: report of three cases. Neurol Res 2004;26:276-281.

71. Santos-Franco JA, Zenteno M, Lee A. Dissecting aneurysms of the vertebrobasilar system. A comprehensive review on natural history and treatment options. Neurosurg Rev 2008;31:131-140; discussion 140.

72. Lylyk P, Cohen JE, Ceratto R, Ferrario A, Miranda C. Combined endovascular treatment of dissecting vertebral artery aneurysms by using stents and coils. J Neurosurg 2001;94:427-432.

73. Joo JY, Ahn JY, Chung YS, et al. Treatment of intraand extracranial arterial dissections using stents and embolization. Cardiovasc Intervent Radiol 2005;28:595602.

74. Fiorella D, Albuquerque FC, Deshmukh VR, et al. Endovascular Reconstruction with the Neuroform Stent as Monotherapy for the Treatment of Uncoilable Intradural Pseudoaneurysms. Neurosurgery 2006;59:291-300.

75. Ahn JY, Han IB, Kim TG, et al. Endovascular Treatment of Intracranial Vertebral Artery Dissections with Stent Placement or Stent-assisted Coiling. AJNR Am J Neuroradiol 2006;27:1514-1520.

76. Amagasaki K, Yagishita T, Yagi S, Kuroda K, Nishigaya K, Nukui H. Serial angiography and endovascular treatment of dissecting aneurysms of the anterior cerebral and vertebral arteries. J Neurosurg 1999;91:682-686.
77. Albuquerque FC, Fiorella DJ, Han PP, Deshmukh VR, Kim LJ, McDougall CG. Endovascular management of intracranial vertebral artery dissecting aneurysms. Neurosurg Focus 2005;18:E3.

78. Conforto AB, Yamamoto F, Evaristo EF, Puglia P, Jr. , Caldas JG, Scaff M. Intracranial vertebral artery dissection presenting as subarachnoid hemorrhage: successful endovascular treatment. Acta Neurol Scand 2001;103:64-68.

79. Coley SC, Clifton A. Dissecting vertebral artery aneurysm: diagnosis and coil embolization. Br J Radiol 1999;72:408-411.

80. Cohen JE, Gomori JM, Umansky F. Endovascular Management of Spontaneous Bilateral Symptomatic Vertebral Artery Dissections. AJNR Am J Neuroradiol 2003;24:2052-2056.

81. Inamasu J, Nakamura Y, Saito R, et al. Endovascular treatment of ruptured vertebral artery dissection in the acute stage. Cerebrovasc Dis 2003;16:306-308.

82. Iihara K, Sakai N, Murao K, et al. Dissecting aneurysms of the vertebral artery: a management strategy. J Neurosurg 2002;97:259-267.

83. Hamada J-i, Kai Y, Morioka M, Yano S, Todaka T, Ushio Y. Multimodal treatment of ruptured dissecting aneurysms of the vertebral artery during the acute stage. J Neurosurg 2003;99:960-966.

84. Halbach VV, Higashida RT, Dowd CF, et al. Endovascular treatment of vertebral artery dissections and pseudoaneurysms. J Neurosurg 1993;79:183-191.

85. Yamaura I, Tani E, Yokota M, et al. Endovascular treatment of ruptured dissecting aneurysms aimed at occlusion of the dissected site by using Guglielmi detachable coils. J Neurosurg 1999;90:853-856.

86. Willing SJ, Skidmore F, Donaldson J, Nobo UL, Chernukha K. Treatment of Acute Intracranial Vertebrobasilar Dissection with Angioplasty and Stent Placement: Report of Two Cases. AJNR Am J Neuroradiol 2003;24:985-989.

87. Saeed AB, Shuaib A, Al-Sulaiti G, Emery D. Vertebral artery dissection: warning symptoms, clinical features and prognosis in 26 patients. Can J Neurol Sci 2000;27:292-296.

88. Rabinov JD, Hellinger FR, Morris PP, Ogilvy CS, Putman CM. Endovascular Management of Vertebrobasilar Dissecting Aneurysms. AJNR Am J Neuroradiol 2003;24:1421-1428.

89. MacKay CI, Han PP, Albuquerque FC, McDougall CG. Recurrence of a vertebral artery dissecting pseudoaneurysm after successful stent-supported coil embolization: case report. Neurosurgery 2003;53:754759; discussion 760-751.

90. Sugiu K, Tokunaga K, Watanabe K, et al. Emergent endovascular treatment of ruptured vertebral artery dissecting aneurysms. Neuroradiology 2005;47:158-164. 91. Sheah K, Lim W, Chan C. Endovascular and 
DOI: 10.2478/romneu-2013-0006

surgical management of vertebral artery dissecting aneurysms presenting with subarachnoid haemorrhage: medium-term experience. Ann Acad Med Singapore 2005;34:262-270.

92. Sawada M, Kaku Y, Yoshimura S, et al. Antegrade recanalization of a completely embolized vertebral artery after endovascular treatment of a ruptured intracranial dissecting aneurysm. J Neurosurg 2005;102:161-166.

93. Ramgren B, Cronqvist M, Romner B, Brandt L, Holtas S, Larsson EM. Vertebrobasilar dissection with subarachnoid hemorrhage: a retrospective study of 29 patients. Neuroradiology 2005;47:97-104.

94. Yasui T, Komiyama M, Nishikawa M, Nakajima H. Subarachnoid hemorrhage from vertebral artery dissecting aneurysms involving the origin of the posteroinferior cerebellar artery: report of two cases and review of the literature. Neurosurgery 2000;46:196-200; discussion 200-191.

95. Kaku Y, Yoshimura S, Yamakawa H, Sakai N. Failure of stent-assisted endovascular treatment for ruptured dissecting aneurysms of the basilar artery. Neuroradiology 2003;45:22-26.

96. Wells-Roth D, Biondi A, Janardhan V, Chapple K, Gobin YP, Riina HA. Endovascular procedures for treating wide-necked aneurysms. Neurosurg Focus 2005;18:E7.

97. Hanel RA, Boulos AS, Sauvageau EG, Levy EI, Guterman LR, Hopkins LN. Stent placement for the treatment of nonsaccular aneurysms of the vertebrobasilar system. Neurosurg Focus 2005;18:E8.

98. Wang Q, Leng B, Song D, Chen G. Fusiform aneurysms of the vertebrobasilar arterial trunk: choice of endovascular methods and therapeutic efficacy. Acta Neurochir (Wien) 2010;152:1467-1476. 